\title{
Association Between Vitamin D Deficiency and COVID-19 Incidence, Complications, and Mortality in 46 Countries: An Ecological Study
}

Javier Mariani, Virna Margarita Marín Giménez, Ivana Bergam, Carlos Tajer, Laura Antonietti, Filipe Inserra, León Ferder, and Walter Manucha

Each patient's immune defenses play a major role in mitigating the impact (ie, morbidity and mortality) of severe acute respiratory syndrome coronavirus 2 (SARS-CoV-2), the virus responsible for coronavirus disease 2019 (COVID-19). Vitamin $\mathrm{D}$ is an important modulator of the immune system. Although serum 25-hydroxyvitamin D levels can be raised through diet or supplements, most vitamin $\mathrm{D}$ in the body is the result of dermal synthesis from ultraviolet radiation. The production of vitamin $\mathrm{D}$ in the skin, however, can be limited by latitude, skin-covering clothes, the use of sunblock, and skin pigmentation. Vitamin D deficiency affects a high percentage of the world population. Serum 25-hydroxyvitamin D levels are suboptimal, not only in specific risk groups but also in adults from many countries. Low vitamin D levels, therefore, represent a risk factor for several different pathologies, including SAR-CoV-2. This study used an ecological design to assess the association between vitamin D deficiency and COVID-19 incidence, complications, and mortality across 46 countries. All data were obtained from published sources. The results of the study suggest an association at the population level between the prevalence of vitamin D deficiency and the risk of being infected with COVID-19, severity of the disease, and risk of dying from it.

Keywords: COVID-19, Vitamin D, Public health preparedness/response, SARS, Infectious disease

\section{INTRODUCTION}

$\mathrm{E}$ ACH PATIENT's IMMUne Defenses play a major role in mitigating the impact (ie, morbidity and mortality) of severe acute respiratory syndrome coronavirus 2 (SARSCoV-2), the virus responsible for coronavirus disease 2019 (COVID-19). ${ }^{1}$ The patient's immune-inflammatory re- sponse is notably involved in the physiopathogenesis of this viral disease, in which multiple cellular pathways and components, including vitamin $\mathrm{D},{ }^{2}$ are implicated. Vitamin $\mathrm{D}$ is an important modulator of the immune system. ${ }^{3}$ Specifically, vitamin $\mathrm{D}$ exerts anti-infectious and immunomodulatory action by improving intercellular barriers by stimulating innate immunity, as well as by modulating adaptive immunity.

Javier Mariani, MD; Carlos D. Tajer, MD; and Laura Antonietti, MD; are Clinical Investigators; Hospital El Cruce, Florencio Varela, Buenos Aires, Argentina. Virna Margarita Marín Giménez, PhD, is an Assistant Professor; Instituto de Investigaciones en Ciencias Químicas, Facultad de Ciencias Químicas y Tecnológicas, Universidad Católica de Cuyo, San Juan, Argentina. Ivana Bergam, PhD, is an Assistant Professor; CROATIA Osiguranje Pension Company for Voluntary Pension Fund Management D.O.O., Zagreb, Croatia. Filipe Inserra, MD, and León Ferder, MD, are Clinical Investigators; Universidad Maimónides, Buenos Aires, Argentina. Walter Manucha, PhD, is a Professor Área de Farmacología, Departamento de Patología, Facultad de Ciencias Médicas, Universidad Nacional de Cuyo, and Director Laboratorio de Farmacología Experimental Básica y Traslacional, Instituto de Medicina y Biología Experimental de Cuyo, Consejo Nacional de Investigaciones Científicas y Tecnológicas; both in Mendoza, Argentina. 
Vitamin D reduces the production of inflammatory cytokines, such as interleukin-2 and interferon-gamma. Furthermore, in close connection, multiple pleiotropic effects have been demonstrated on the actions of vitamin $\mathrm{D}$ at the anti-inflammatory and immunomodulatory level with positive results in studies with influenza, coronavirus, and other respiratory infections. ${ }^{4}$

Vitamin D levels, measured by serum 25-hydroxyvitamin D $[25(\mathrm{OH}) \mathrm{D}]$ concentration, increase after exposure of skin to sunlight and decrease during the "dark months" of the year (when skin is usually covered), fluctuating from $30 \%$ to $50 \%$ in some cases. ${ }^{5-7}$ Although $25(\mathrm{OH}) \mathrm{D}$ levels can be raised through diet or supplements, most vitamin $\mathrm{D}$ in the body (between $50 \%$ and $90 \%$ ) is the result of dermal synthesis from ultraviolet radiation. The production of vitamin $\mathrm{D}$ in the skin, however, can be limited by latitude, skin-covering clothes, the use of sunblock, and skin pigmentation. ${ }^{8}$

In addition to its nonenzymatic synthesis, vitamin D is enzymatically converted into its active form-1,25dihydroxyvitamin $\mathrm{D}\left[1,25(\mathrm{OH})_{2} \mathrm{D}\right]$ - in the kidneys and liver mainly, although it is also produced in other organs, tissues, and cells, such as prostate, placenta, lungs, brain, and immune cells. ${ }^{9,10}$ Vitamin $\mathrm{D}$ is a steroid hormone, and 1,25$(\mathrm{OH})_{2} \mathrm{D}$ is the ligand for the vitamin $\mathrm{D}$ receptor. Cells lacking the vitamin $\mathrm{D}$ receptor are the exception rather than the rule, and this widespread distribution underlies the potential myriad of physiological actions for vitamin D. ${ }^{11}$

International consensus on the definition of vitamin D deficiency is lacking; however, it is accepted that a serum $25(\mathrm{OH}) \mathrm{D}$ level of 20 nanograms per milliliter $(\mathrm{ng} / \mathrm{mL})^{*}$ is the threshold of sufficiency for $97.5 \%$ of the population in terms of bone health. ${ }^{5}$ Vitamin D deficiency is highly prevalent and affects a high percentage of the world population. ${ }^{12}$ Serum $25(\mathrm{OH}) \mathrm{D}$ levels are not only suboptimal in specific risk groups but also in adults from many countries-especially in the Middle East and Asia, where vitamin $\mathrm{D}$ deficiency in adults is highly prevalent. ${ }^{13}$ The lack of sufficient levels of serum vitamin $\mathrm{D}$ in communities has shown greater susceptibility to a broad spectrum of diseases, in addition to the classically described bone disorders. ${ }^{14,15}$ It has been found that low vitamin D levels represent a risk factor for several different pathologies, such as autoimmune, neurodegenerative, and cardiovascular diseases, as well as diabetes, osteoporosis, cancer, and infectious diseases such as viral infections. ${ }^{12}$ Accordingly, vitamin $\mathrm{D}$ has been associated with the current pandemic because of its potential role in reducing the risk of SARCoV-2 infection. ${ }^{16,17}$

Of special interest, vitamin $\mathrm{D}$ has important antiviral properties, including the induction of cathelicidin and $\beta 2$ defensins synthesis. ${ }^{18}$ Cathelicidin and $\beta 2$-defensins exert

\footnotetext{
*Serum $25(\mathrm{OH}) \mathrm{D}$ levels are also measured using nanomoles per liter. The vitamin D deficiency threshold of $20 \mathrm{ng} / \mathrm{mL}$ is equalivent to $50 \mathrm{nmol} / \mathrm{L}$.
}

significant antibiotic and antiviral effects. These pluripotent peptides have a crucial role in innate immunity, and their regulation is abnormal in hypovitaminosis $\mathrm{D}$.

This study aimed to assess the association of vitamin D deficiency on COVID-19 incidence, complications, and mortality in 46 countries.

\section{Methods}

\section{Design}

This study used an ecological design to correlate COVID-19 infection risk and outcome variables and vitamin $\mathrm{D}$ deficiency levels at the country level. All data were obtained from online published sources. Since all of the data were anonymized and publicly available, no ethical approval was sought.

\section{Vitamin D Deficiency}

Vitamin D deficiency was defined as a $25(\mathrm{OH}) \mathrm{D}$ serum level of less than $20 \mathrm{ng} / \mathrm{mL} .{ }^{5,19}$ Data for national prevalence estimates of vitamin D deficiency were obtained from population studies reported elsewhere, ${ }^{5,13,20}$ and are expressed as the estimated percentage of population with vitamin $\mathrm{D}$ deficiency. If more than 1 estimate was found, the more conservative (ie, the lower prevalence) and those corresponding to the broadest population representation (ie, the majority of population subgroups) were used.

\section{COVID-19 Cases, Tests, and Mortality}

Data on the number of COVID-19 cases, number of tests performed, number of deaths from COVID-19, and population were obtained from Worldometer. ${ }^{21}$ This website collects and publish information from country's official channels. We used data as published on July 4, 2020. We also obtained population data from this website to estimate the population incidence of COVID-19 infection and the population COVID-19 death rates.

Cases are reported as the cumulative number of individuals who tested positive for COVID-19 with a confirmed laboratory result and as rates per millions of people. Tests are reported as the cumulative number of diagnostic tests performed in a given country and as the number of tests per millions of people. Mortality is reported as the cumulative number of COVID-19 deaths and the rate per millions of people. All deaths for every country are counted in the rate, from the inception of each country's first case.

\section{Gross Domestic Product}

Data on national gross domestic product (GDP) were obtained from the World Bank's DataBank. GDP for the year 2019 (in billions of US dollars) were used for analysis. ${ }^{22}$ 


\section{Data Extraction}

All data were extracted by 2 researchers to a worksheet designed ad hoc. All data were extracted as published from the aforementioned sources without further modifications. All discrepancies were resolved by consensus. Only countries with available data for vitamin $\mathrm{D}$ status were included (data for COVID-19 indicators and GDP were available for all countries). After extraction, the case fatality ratio was computed as the cumulative number of deaths per cumulative number of cases, and the positivity ratio was computed as the cumulative number of cases per cumulative number of tests performed.

\section{Statistical Analysis}

Descriptive statistics were expressed as medians and interquartile ranges (IQR). Comparisons across vitamins D deficiency quintiles were conducted using the KruskalWallis test. The correlation between COVID-19 incidence, positivity ratio, case fatality ratio, and death rate were evaluated using Spearman's correlation coefficient. Furthermore, scatterplots with nonlinear regression lines (ie, local regression) were constructed to present correlation analysis.

To assess the association between COVID-19 indicators and vitamin $\mathrm{D}$ deficiency, multivariate Poisson regression models were constructed. Quintiles of vitamin D deficiency at the population level were included as independent variables, and COVID-19 indicators as dependent variables. All models were adjusted for GDP using log transformation. Results are reported as incidence rate ratios (IRR) with their corresponding $95 \%$ confidence intervals. All tests were 2 -tailed and a $P$ value of less than .05 is considered statistically significant. All analyses were conducted with R: A Language and Environment for Statistical Computing, version 4.0 for MacOS ( $\mathrm{R}$ Foundation for Statistical Computing, Vienna, Austria).

\section{Results}

Overall, 46 countries with complete data were included in the analysis. Table 1 presents a summary of COVID-19 and GDP indicators by quintiles of vitamin D deficiency. The overall median percentage of vitamin D deficiency was 49.0 (IQR 26.8 to 56.6)-from 13.0 (IQR 7.5 to 17.0) in the first quintile to 65.0 (IQR 60.0 to 68.9 ) in the fifth quintile.

The overall median number of COVID-19 cases was 37,900 (IQR 4,400 to 153,600), with a median incidence rate of 2,221.5 (IQR 330.2 to 4,145.2) cases. The median number of COVID-19 deaths was 900 (IQR 100 to 8,700), with a death rate of 53.0 (IQR 8.0 to 231.0). The median case fatality ratio was 4.1 (IQR 1.4 to 6.1 ). The median test rate was 46,000 (IQR 20,000 to 106,000) and the positivity rate was $3.6 \%$ (IQR 1.1 to 7.3 ).

\section{Vitamin D Deficiency and COVID-19 Incidence}

There was a positive and statistically significant correlation between the incidence of COVID-19 infection and vitamin $\mathrm{D}$ deficiency $(R=0.39 ; P=.0075)$ (Figure 1$)$. Figure 2 and Table 2 show the results of Poisson regression models. Incidence rate ratios were positively associated with quintiles of vitamin D deficiency.

\section{Vitamin D Deficiency and COVID-19 Positivity}

There was a positive correlation $(R=0.36 ; P=.016)$ between vitamin $\mathrm{D}$ deficiency and the positivity ratio (Figure 1). In Poisson regression models (adjusted for GDP), the association between the positivity ratio and vitamin D deficiency was evident and the relationships were strongest for the second quintile (IRR 2.01; 95\% CI, 1.34 to $3.06 ; P=.001$ ), the fourth quintile (IRR $1.72 ; 95 \% \mathrm{CI}$, 1.15 to $2.62 ; P<.010$ ) and the fifth quintile (IRR 2.17; 95\% CI, 1.48 to 3.26; $P<.001$ ) (Figure 2, Table 2).

\section{Vitamin D Deficiency and Case Fatality Ratio and Death Rate}

There were positive and statistically significant correlations between vitamin $\mathrm{D}$ deficiency and the case fatality ratio $(R=0.40 ; P=.007)$ and death rate $(R=0.38 ; P=.011)$ (Figure 1). For the case fatality ratio, the IRR in the fifth quintile was more than double the IRR in the first quintile, after adjusting for GDP. The death rate was higher in the third, fourth, and fifth quintiles (Figure 2, Table 2).

\section{Discussion}

The results of the present study suggest an association at the population level between the prevalence of vitamin $\mathrm{D}$ deficiency and the risk of being infected with COVID-19, severity of the disease, and risk of dying from it. These associations were consistent in both correlation analyses and Poisson regression models adjusted for GDP (the indicator for socioeconomic level). This study extends those observations by quantifying the association between incidence and severity of COVID-19 and documenting the association with the case fatality ratio. A strength of this study is the inclusion and analysis of information from 46 countries around the world.

A 2010 study showed that people with a mean serum $25(\mathrm{OH}) \mathrm{D}$ concentration level of more than $38 \mathrm{ng} / \mathrm{mL}-$ over a period of 4 to 5 months during fall and winter-had less than half the incidence rate of acute viral respiratory infections seen in those with lower concentrations. ${ }^{23}$ Another ecological study found that communities exposed to higher solar ultraviolet type B radiation doses-both in 


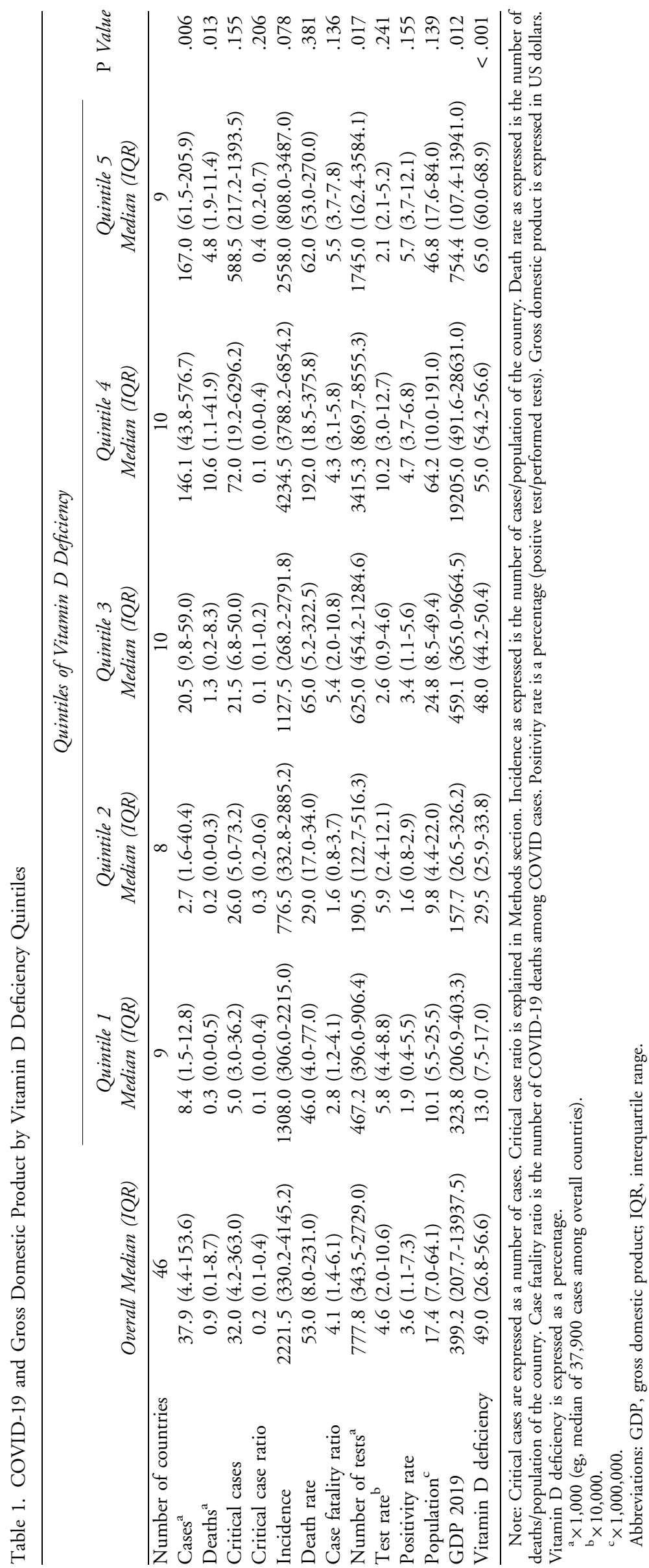



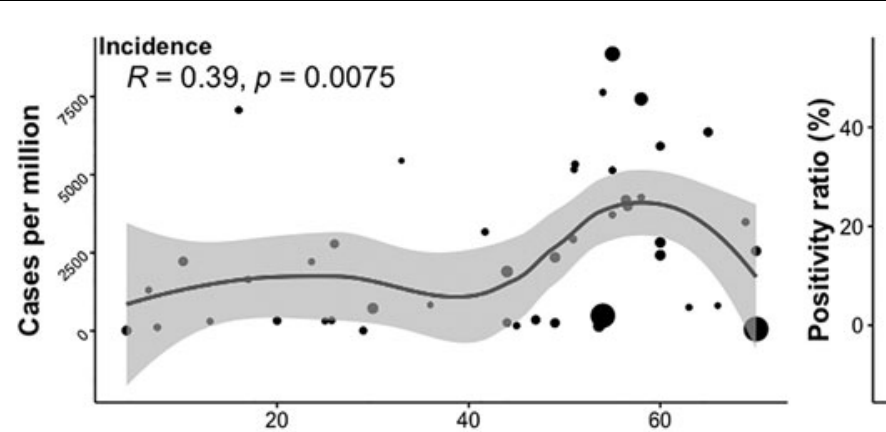

Positivity ratio

$R=0.36, p=0.016^{\circ}$
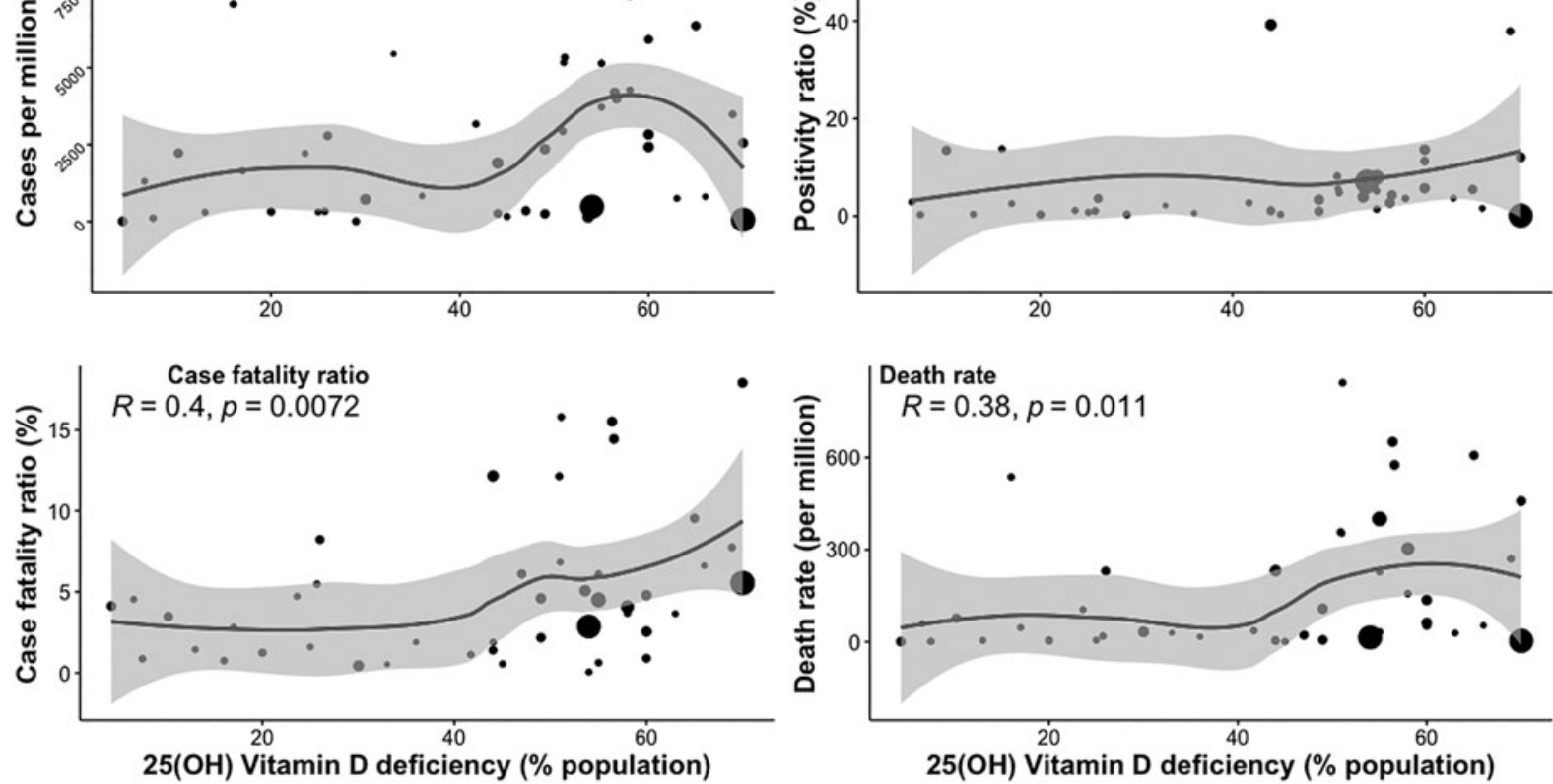

Figure 1. Correlation between vitamin D deficiency and COVID-19 indicators.

summer and in winter-had a significantly lower case fatality rate during the 1918-1919 influenza pandemic in the United States. ${ }^{24}$ One study in South Korea found that a serum $25(\mathrm{OH}) \mathrm{D}$ concentration of more than $20 \mathrm{ng} / \mathrm{mL}$ was associated with an adjusted odds ratio for mortality of 0.94 (95\% CI, 0.90 to 0.99 ) for those who developed community-acquired pneumonia. ${ }^{25}$
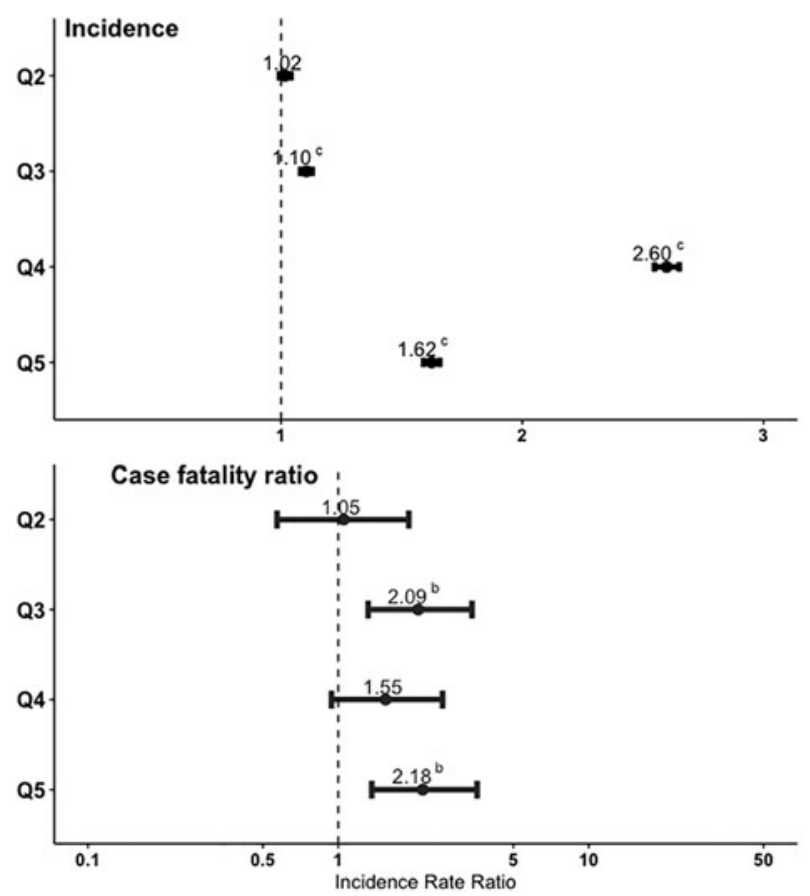

Evidence suggests that vitamin D could play a protective role against COVID-19 infection. A 2020 review of evidence $^{26}$ included the following as evidence supporting the protective role of vitamin D: the occurrence of outbreaks during the winter (when serum levels of vitamin D are lowest), the low number of cases observed in the southern hemisphere near the end of summer, the association

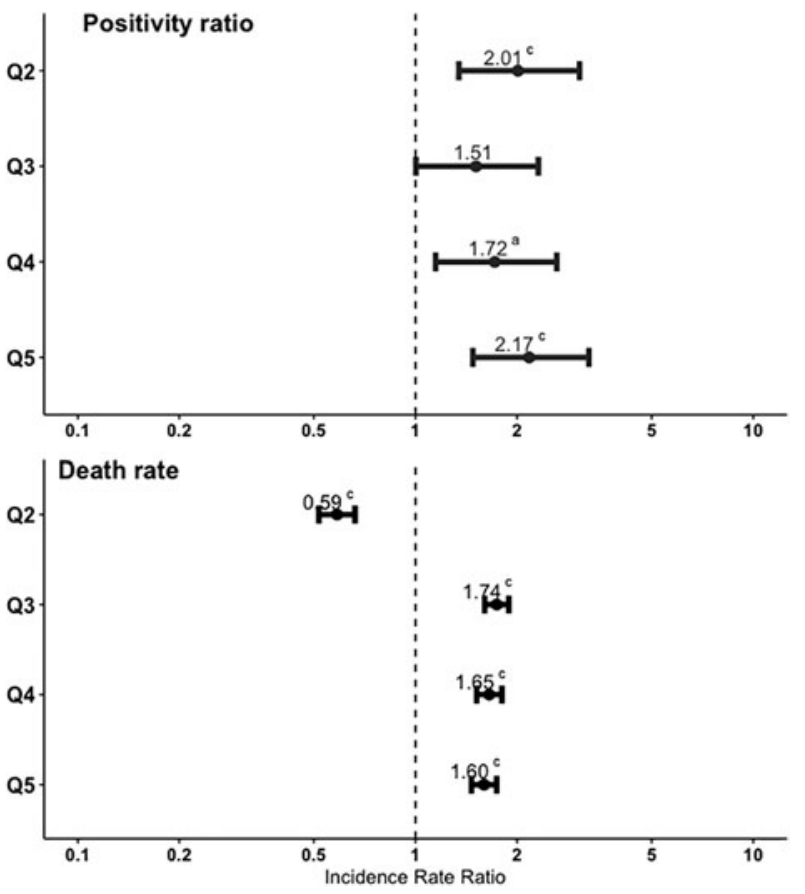

Figure 2. Poisson regression models assessing the association between COVID-19 indicators and vitamin D deficiency quintiles. $\mathrm{a}=P$ value $<.05 ; \mathrm{b}=P$ value $<.01 ; \mathrm{c}=P$ value $<.001$. Abbreviations: IRR, incidence rate ratio; $\mathrm{Q}$, quintile. 
Table 2. Results of Poisson Regression Models for COVID-19 Indicators by Vitamin D Deficiency Quintile

\begin{tabular}{|c|c|c|}
\hline Vitamin D Deficiency Quintiles & $\operatorname{IRR}(95 \% C I)$ & P Value \\
\hline \multicolumn{3}{|l|}{ Incidence } \\
\hline Q1 (reference) & 1 & - \\
\hline Q2 & $1.02(0.99-1.04)$ & .159 \\
\hline Q3 & $1.1(1.08-1.13)$ & $<.001$ \\
\hline Q4 & $2.6(2.55-2.65)$ & $<.001$ \\
\hline Q5 & $1.62(1.59-1.66)$ & $<.001$ \\
\hline \multicolumn{3}{|l|}{ Positivity ratio } \\
\hline Q1 (reference) & 1 & - \\
\hline Q2 & $2.01(1.34-3.06)$ & .001 \\
\hline Q3 & $1.51(1-2.31)$ & .052 \\
\hline Q4 & $1.72(1.15-2.62)$ & .010 \\
\hline Q5 & $2.17(1.48-3.26)$ & $<.001$ \\
\hline \multicolumn{3}{|l|}{ Case fatality ratio } \\
\hline Q1 (reference) & 1 & - \\
\hline Q2 & $1.05(0.57-1.91)$ & .871 \\
\hline Q3 & $2.09(1.32-3.42)$ & .002 \\
\hline Q4 & $1.55(0.94-2.61)$ & .093 \\
\hline Q5 & $2.18(1.36-3.59)$ & .002 \\
\hline \multicolumn{3}{|l|}{ Death rate } \\
\hline Q1 (reference) & 1 & - \\
\hline Q2 & $0.59(0.52-0.66)$ & $<.001$ \\
\hline Q3 & $1.74(1.6-1.89)$ & $<.001$ \\
\hline Q4 & $1.65(1.52-1.8)$ & $<.001$ \\
\hline Q5 & $1.6(1.47-1.74)$ & $<.001$ \\
\hline
\end{tabular}

All models were adjusted for GDP using log transformation Abbreviations: CI, confidence interval; GDP, gross domestic product; IRR, incidence rate ratio; $Q$, quintile.

between vitamin $\mathrm{D}$ deficiency and the development of acute respiratory distress syndrome, and that mortality rates increase in older adults and in patients with chronic diseases (both age and chronic disease comorbidity are associated with reduced serum $25(\mathrm{OH}) \mathrm{D}$ concentrations). It has been suggested that a strong correlation exists between latitude, which directly influences a person's exposure to sunlight, and mortality following COVID-19 infection. ${ }^{27,28}$ Low mortality rates observed in Nordic countries are exceptions that could be explained by strong supplementation and food fortification with vitamin D carried out in these countries. ${ }^{29}$ Epidemiological studies in Europe and the United States have also suggested an inverse relationship between vitamin D levels and COVID-19 risk. ${ }^{30,31}$ Vitamin D supplementation has consistently been considered useful in the treatment of COVID-19 infection. ${ }^{32}$

Furthermore, a 2020 study determined that vitamin D may interfere with the functionality of $70 \%$ of SARS-CoV2 proteins through alteration of the expression of $25 \%$ of human genes encoding protein targets of SARS-CoV-2. ${ }^{33}$ Deficiency in vitamin D would, therefore, contribute to susceptibility to infection and morbidity and mortality due to COVID-19. It has also been reported that one of the main defenses against uncontrolled inflammation, especially of viral origin, is represented by regulatory $T$ cells. Many patients with COVID-19 have been found to have reduced levels of regulatory $\mathrm{T}$ cells, which may be increased by supplementation with vitamin $\mathrm{D} .{ }^{34}$

\section{Limitations}

This study has several limitations that are important to consider when interpreting the results. Because it is an ecological study, the results do not mean that individuals with vitamin D deficiency are at increased risk of COVID19 infection and mortality (this would be an ecological fallacy). However, evidence from observational studies suggest that the relationship between COVID-19 risk and mortality remains at the level of the individual participants.

Because the number of countries included in our analysis was determined by the countries with available population estimates for $25(\mathrm{OH}) \mathrm{D}$ deficiency identified in our search, we acknowledge that the inclusion of all countries with reported COVID-19 data could change the results. However, as discussed previously, observations from other studies with different designs are consistent with our results.

\section{Conclusion}

The results of the present study suggest that vitamin D deficiency as associated with an increased risk of COVID19 infection and mortality across a wide range of countries. Since the accumulating body of evidence strongly suggests the risks of vitamin $\mathrm{D}$ deficiency and the benefits of vitamin $\mathrm{D}$ supplementation, there is an urgent need for evidence from well-designed clinical trials evaluating vitamin D supplementation for the prevention and treatment of COVID-19 in different settings.

\section{AcKnowledgments}

This work was supported by grants from the Research and Technology Council of Cuyo University (SECyT), Mendoza, Argentina (grant no. (PICT 2016-4541), and from the National Agency for Scientific and Technological Promotion (ANPCYT) through the Scientific and Technological Research Fund (FONCYT; grant no. IP-COVID-19-931), both of which were awarded to Walter Manucha.

\section{REFERENCES}

1. Raoult D, Zumla A, Locatelli F, et al. Coronavirus infections: epidemiological, clinical and immunological features and hypotheses. Cell Stress. 2020;4(4):66-75.

2. Aranow C. Vitamin D and the immune system. I Investig Med. 2011;59(6):881-886.

3. Arnljots R, Snaebjörnsson Arnljots E, Thorn J, et al. Bacteriuria and vitamin $\mathrm{D}$ deficiency: a cross sectional study of 385 nursing home residents. BMC Geriatr. 2019;19(1):381.

4. Mansur JL, Tajer C, Mariani J, et al. Vitamin D high doses supplementation could represent a promising alternative to 
prevent or treat COVID-19 infection. Clin Investig Arterioscler. 2020;32(6):267-277.

5. Lips P, Cashman KD, Lamberg-Allardt C, et al. Current vitamin D status in European and Middle East countries and strategies to prevent vitamin D deficiency: a position statement of the European Calcified Tissue Society. Eur J Endocrinol. 2019;180(4):P23-P54.

6. Grant WB, Bhattoa HP, Boucher BJ. Seasonal variations of U.S. mortality rates: Roles of solar ultraviolet-B doses, vitamin D, gene expression, and infections. J Steroid Biochem Mol Biol. 2017;173:5-12.

7. Cinar N, Harmanci A, Yildiz BO, et al. Vitamin D status and seasonal changes in plasma concentrations of 25-hydroxyvitamin D in office workers in Ankara, Turkey. Eur J Intern Med. 2014;25(2):197-201.

8. Lips P. Worldwide status of vitamin D nutrition. J Steroid Biochem Mol Biol. 2010;121(1-2):297-300.

9. Adams JS, Hewison M. Extrarenal expression of the 25hydroxyvitamin D-1-hydroxylase. Arch Biochem Biophys. 2012;523(1):95-102.

10. Zehnder D, Bland R, Williams MC, et al. Extrarenal expression of 25-hydroxyvitamin $\mathrm{d}(3)-1$ alpha-hydroxylase. $J$ Clin Endocrinol Metab. 2001;86(2):888-894.

11. Rosen CJ, Adams JS, Bikle DD, et al. The nonskeletal effects of vitamin D: an Endocrine Society scientific statement. Endocr Rev. 2012;33(3):456-492.

12. Ferder M, Inserra F, Manucha W, et al. The world pandemic of vitamin D deficiency could possibly be explained by cellular inflammatory response activity induced by the reninangiotensin system. Am J Physiol Cell Physiol. 2013;304(11): C1027-1039.

13. Van Schoor N, Lips P. Worldwide vitamin D status. In: Feldman D, Pike JW, Bouillon R, Giovannucci E, Goltzman D, Hewison M, eds. Vitamin D: Volume 2: Health, Disease and Therapeutics. 4th ed. London: Academic Press; 2018:15-40.

14. Saponaro F, Marcocci C, Zucchi R. Vitamin D status and cardiovascular outcome. J Endocrinol Invest. 2019;42(11): 1285-1290.

15. Yamamoto EA, Jørgensen TN. Relationships between vitamin D, gut microbiome, and systemic autoimmunity. Front Immunol. 2020;10:3141.

16. Grant WB, Lahore H, McDonnell SL, et al. Evidence that vitamin D supplementation could reduce risk of influenza and COVID-19 infections and deaths. Nutrients. 2020; 12(4):988.

17. Trovas G, Tournis S. Vitamin D and COVID-19. Hormones (Athens). July 14, 2020. doi:10.1007/s42000-020-00231-9

18. Amado Diago CA, García-Unzueta MT, Fariñas MC, et al. Calcitriol-modulated human antibiotics: new pathophysiological aspects of vitamin D. Endocrinol Nutr. 2016;63(2): 87-94.

19. Alshahrani F, Aljohani N. Vitamin D: deficiency, sufficiency and toxicity. Nutrients. 2013;5(9):3605-3616.

20. Manios Y, Moschonis G, Lambrinou CP, et al. A systematic review of vitamin $\mathrm{D}$ status in southern European countries. Eur J Nutr. 2018;57(6):2001-2036.

21. Worldometer. COVID-19 coronavirus pandemic. Accessed November 30, 2020. https:/www.worldometers.info/ coronavirus/

22. World Bank. World Bank Open Data. Accessed November 30, 2020. https://data.worldbank.org/
23. Sabetta JR, DePetrillo P, Cipriani RJ, et al. Serum 25-hydroxyvitamin $\mathrm{d}$ and the incidence of acute viral respiratory tract infections in healthy adults. PLoS One. 2010;5(6):e11088.

24. Grant WB, Giovannucci E. The possible roles of solar ultraviolet- $\mathrm{B}$ radiation and vitamin $\mathrm{D}$ in reducing case-fatality rates from the 1918-1919 influenza pandemic in the United States. Dermatoendocrinol. 2009;1(4):215-219.

25. Kim HJ, Jang JG, Hong KS, et al. Relationship between serum vitamin D concentrations and clinical outcome of community-acquired pneumonia. Int $J$ Tuberc Lung Dis. 2015;19(6):729-734.

26. Grant WB, Lahore H, McDonnell SL, et al. Evidence that vitamin $\mathrm{D}$ supplementation could reduce risk of influenza and COVID-19 infections and deaths. Nutrients. 2020;12(4):988.

27. Rhodes JM, Subramanian S, Laird E, et al. Editorial: low population mortality from COVID-19 in countries south of latitude 35 degrees North supports vitamin D as a factor determining severity. Aliment Pharmacol Ther. 2020;51(12): 1434-1437.

28. Whittemore PB. COVID-19 fatalities, latitude, sunlight, and vitamin D. Am J Infect Control. 2020;48(9):1042-1044.

29. Mitchell F. Vitamin-D and COVID-19: do deficient risk a poorer outcome? Lancet Diabetes Endocrinol. 2020;8(7):570.

30. Ilie PC, Stefanescu S, Smith L. The role of vitamin D in the prevention of coronavirus disease 2019 infection and mortality. Aging Clin Exp Res. 2020;32(7):1195-1198.

31. Mendy A, Apewokin S, Wells AA, et al. Factors associated with hospitalization and disease severity in a racially and ethnically diverse population of COVID-19 patients. Preprint. medRxiv. Posted June 27, 2020. doi:10.1101/ 2020.06.25.20137323

32. Ebadi M, Montano-Loza AJ. Perspective: improving vitamin D status in the management of COVID-19. Eur J Clin Nutr. 2020;74(6):856-859.

33. Glinsky GV. Tripartite combination of candidate pandemic mitigation agents: vitamin $\mathrm{D}$, quercetin, and estradiol manifest properties of medicinal agents for targeted mitigation of the COVID-19 pandemic defined by genomics-guided tracing of SARS-CoV-2 targets in human cells. Biomedicines. 2020; 8(5):129.

34. Weir EK, Thenappan T, Bhargava M, et al. Does vitamin D deficiency increase the severity of COVID-19? Clin Med (Lond). 2020;20(4):e107-e108.

Manuscript received August 20, 2020;

revision returned October 22, 2020;

accepted for publication October 27, 2020.

Address correspondence to: Walter Manucha, PhD

Director Laboratorio de Farmacología Experimental Básica y Traslacional Instituto de Medicina y Biología Experimental de Cuyo CCT CONICET Mendoza Av. Ruiz Leal s/n

Parque General San Martín PC 5500 Mendoza Argentina

Email:wmanucha@fcm.uncu.edu.ar 